\title{
Hypocaloric Diet and Regular Moderate Aerobic Exercise Is an Effective Strategy to Reduce Anthropometric Parameters and Oxidative Stress in Obese Patients
}

\author{
Liliana Gutierrez-Lopez ${ }^{a}$ b Jose Ruben Garcia-Sanchez ${ }^{b}$ \\ Maria de Jesus Rincon-Viquez ${ }^{b} \quad$ Eleazar Lara-Padilla ${ }^{a}$ b \\ Martha P. Sierra-Vargas ${ }^{c}$ Ivonne M. Olivares-Corichib \\ a Department of Sport and Informatics, Pablo de Olavide University, Sevilla, Spain, \\ ${ }^{b}$ Postgraduate Studies and Research Section, School of Medicine National Polytechnique \\ Institute, 'Department of Biochemistry and Environmental Medicine, National Institute of \\ Respiratory Diseases 'Ismael Cosio Villegas, México City, Mexico
}

Key Words

Diet $\cdot$ Exercise $\cdot$ Insulin resistance $\cdot$ Obesity $\cdot$ Weight loss $\cdot$ Free radicals $\cdot$ Oxidative stress $\cdot$

Reactive oxygen species

\begin{abstract}
Background: Studies show that diet and exercise are important in the treatment of obesity. The aim of this study was to determine whether additional regular moderate aerobic exercise during a treatment with hypocaloric diet has a beneficial effect on oxidative stress and molecular damage in the obese patient. Methods: Oxidative stress of 16 normal-weight (NW) and 32 obese 1 (O1) subjects (BMI $30-34.9 \mathrm{~kg} / \mathrm{m}^{2}$ ) were established by biomarkers of oxidative stress in plasma. Recombinant human insulin was incubated with blood from NW or O1 subjects, and the molecular damage to the hormone was analyzed. Two groups of treatment, hypocaloric diet (HD) and hypocaloric diet plus regular moderate aerobic exercise (HDMAE), were formed, and their effects in obese subjects were analyzed. Results: The data showed the presence of oxidative stress in $\mathrm{O} 1$ subjects. Molecular damage and polymerization of insulin was observed more frequently in the blood from $\mathrm{O} 1$ subjects. The treatment of $\mathrm{O} 1$ subjects with HD decreased the anthropometric parameters as well as oxidative stress and molecular damage, which was more effectively prevented by the treatment with HDMAE. Conclusion: HD and HDMAE treatments decreased anthropometric parameters, oxidative stress, and molecular damage in $\mathrm{O} 1$ subjects.




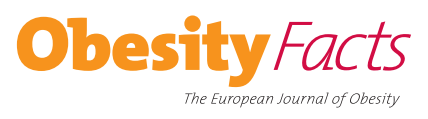

\begin{tabular}{l|l}
\hline \multicolumn{2}{l}{ Obes Facts 2012;5:12-22 } \\
\hline DOI: 10.1159/000336526 & $\begin{array}{l}\text { C) 2012 S. Karger GmbH, Freiburg } \\
\text { www.karger.com/ofa }\end{array}$ \\
\hline Published online: March 2, 2012 &
\end{tabular}

Gutierrez-Lopez et al.: Strategy to Improve Oxidative Stress in Obese Patients

\section{Introduction}

The incidence of obesity in adults and children is increasing globally. Obesity has previously been considered a problem of developed countries, but this disease also affects the developing countries. In fact, the increasing prevalence of obesity has led the World Health Organization (WHO) to refer to obesity as a 'global epidemic'. Human obesity is associated with the development of complications such as cardiovascular disease, stroke, depression, and type 2 diabetes $[1,2]$, which are spreading rapidly across poor and middle-income countries. Experimental animal models have confirmed these correlations. Obesity is the most powerful risk factor for the development of type 2 diabetes, and the association between these two disorders appears to be due to the increased circulating levels of tumor necrosis factor- $\alpha$ within obese individuals [3], which contributes to dysregulation of adipocytokines in the accumulated fat and the induction of systemic oxidative stress [4, 5]. Insulin resistance is considered the key primary defect underlying the development of type 2 diabetes, an event that has been frequently associated with the state of inflammation present in the obese patient $[6,7]$. However, our in vitro studies have shown that oxidative stress can generate structural and functional changes to insulin in blood, suggesting that molecular damage could also contribute to the impairment of the hormone [8] and thereby underlining the importance of oxidative stress in the pathogenesis of obesity and its relationship with the development of type 2 diabetes.

A growing number of studies have shown that diet and exercise are important in the treatment of diseases, including obesity $[9,10]$. In fact, it could be shown that regular exercise has beneficial impact on the antioxidant capacity, protects against the harmful effects of oxidative stress and prevents cellular damage $[11,12]$. Regular moderate aerobic exercise is critical in obesity treatment because it reduces total cholesterol and low-density lipoprotein cholesterol (LDL-C) and increases high-density lipoprotein cholesterol (HDL-C) [13, 14]. While exercise confers multiple health benefits $[15,16]$, it is important to establish strategies that improve the antioxidant capacity during the treatment of obese patients. The aim of this study was to determine whether regular moderate aerobic exercise during a treatment with hypocaloric diet (HD) has an additional beneficial effect on oxidative stress and molecular damage in the obese patient.

\section{Material and Methods}

\section{Patients and Healthy Volunteers}

The ethics and research committees from the School of Medicine of the National Polytechnique approved the protocol of this study, and written informed consent was obtained from all participants. The trial was conducted in accordance with the ethical principles originating in the Declaration of Helsinki of 1975 as revised in 1983, and it was consistent with Good Clinical Practice Guidelines. BMI was used to classify the patients. BMI was calculated by dividing a person's weight in kilograms (kg) by the person's height in meters squared $\left(\mathrm{m}^{2}\right)$. According to the World Health Organization (WHO), subjects were classified as normal weight (NW) with a BMI of 18.5 to $24.9 \mathrm{~kg} / \mathrm{m}^{2}$ and as obese 1 (O1) with a BMI of 30-34.9 $\mathrm{kg} / \mathrm{m}^{2} .3201$ patients were randomized to make the following groups: the HD group $(\mathrm{N}=16)$ and the HD plus regular moderate aerobic exercise (HDMAE) group $(\mathrm{N}=16)$. Both were treated for 3 months. As a control group, $16 \mathrm{NW}$, healthy volunteers were used. Anthropometric measurements were evaluated in each group by the same examiner (table 1). In addition, all participants had to meet the following criteria before enrollment in the study: i) no participation in regular physical activity; ii) no current chronic health problems; iii) no smoking history; iv) no cardiovascular, metabolic or respiratory disease; and v) no consumption of antioxidant supplements (vitamin C, vitamin E, alpha-lipoic acid, beta-carotene, probucol, carvedilol, and iron chelators) or prooxidants (primaquine and iron) within the last 6 months. 
Table 1. Anthropometric parameters of the groups in study ${ }^{\mathrm{a}}$

\begin{tabular}{lll}
\hline Anthropometric parameters & $\begin{array}{l}\text { Normal weight } \\
(\mathrm{N}=16)\end{array}$ & $\begin{array}{l}\text { Obese } 1 \\
(\mathrm{~N}=32)\end{array}$ \\
\hline Weight, kg & $54.70 \pm 1.70$ & $84.27 \pm 14.0^{*}$ \\
BMI, kg/m² & $21.40 \pm 0.40$ & $33.16 \pm 3.90^{*}$ \\
Body fat, \% & $22.0 \pm 3.22$ & $40.78 \pm 4.73^{*}$ \\
Waist circumference, cm & $79.0 \pm 4.52$ & $98.72 \pm 9.83^{*}$ \\
Hip circumference, cm & $93.0 \pm 3.71$ & $113.92 \pm 9.30^{*}$ \\
Waist-to-hip ratio & $0.83 \pm 0.03$ & $0.86 \pm 0.07^{*}$ \\
Age, years & $25.60 \pm 1.40$ & $42.36 \pm 11.40$ \\
Height, m & $1.57 \pm 0.05$ & $1.58 \pm 0.71$ \\
\hline
\end{tabular}

aData are expressed as means $\pm \mathrm{SD}$, analyzed by t student.

*p $<0.0001$.

\section{Blood Samples}

A sample of blood $(10 \mathrm{ml})$ was obtained from the antecubital vein of the arm. $3 \mathrm{ml}$ of blood were used to obtain plasma and to determine the biomarkers of oxidative stress damage (TBARS, dityrosines, and carbonyl group). $6 \mathrm{ml}$ of blood were used in the assays for oxidation and structural changes of recombinant human insulin (see below). At the end of HD or HDMAE (3 months), the same amount of blood was obtained, and oxidative stress biomarkers and molecular damage to human recombinant insulin were analyzed again.

Dietary Assessment

Before beginning participation, subjects were with provided dietary education using references such as the Official Mexican Norm for the control and management of obesity. Subjects were encouraged to avoid excessive consumption of high-fat foods, to reduce portion sizes, and to increase daily intake of complex carbohydrates, lean meats, dairy products, fruits, and vegetables.

Nutritional history for each patient was taken, and a personal diet with a $20 \%$ caloric restriction was designed for each patient. The caloric restriction was determined according to the Harris Benedict equation using equivalent foods. The equivalent foods were determined using the equivalents list from the American Heart Association of Diet and the Mexican System of Equivalents. The energetic balance of the diet was $50 \%$ carbohydrates, $20 \%$ proteins, and $30 \%$ fat.

\section{Regular Moderate Aerobic Exercise}

The heart rate required during regular moderate aerobic exercise for each patient was determined by the formula 220 minus age multiplied by 60 or $70 \%$. Patients were provided with a treadmill for exercise training. They were encouraged to exercise for $30 \mathrm{~min} 3$ times a week for a period of 3 months. Patients assigned to the group without physical activity continued their sedentary lifestyle.

\section{Plasma Biomarkers of Oxidative Stress Damage}

To measure the amount of lipid oxidative products and chemically modified proteins formed by oxidative injury in plasma, $3 \mathrm{ml}$ samples of blood from the groups were utilized. Plasma was obtained by centrifugation at $1,400 \mathrm{~g}$ for $15 \mathrm{~min}$ and utilized for numerous assays: i) Circulating lipid damage was analyzed using thiobarbituric acid-reacting products (TBARS) [17]. Aliquots of $100 \mu$ l were utilized to measure the absorbance at $529 \mathrm{~nm} .1,1,3,3$-tetramethoxypropane (Sigma-Aldrich, St. Louis, MO, USA) was used as a standard. ii) The capacity of proteins to react with nitroblue tetrazolium (NBT) producing formazan was utilized as an indirect means of analyzing proteins modified by oxidative stress. The reaction was carried out with $10 \mu \mathrm{l}$ of plasma, and the absorbance was measured at $530 \mathrm{~nm}$ to detect the formazan [18]. The molar extinction coefficient for formazan, $\mathrm{E}=15 \mathrm{mmol} / \mathrm{l} / \mathrm{cm}$, was utilized to calculate its concentration. iii) Tyrosine dimers (dityrosine) were determined by measuring fluorescence at excitation and emission wavelengths of 325 and $410 \mathrm{~nm}$, respectively, from an aliquot of $100 \mu \mathrm{l}$ of plasma [19]. 
The final concentration of dityrosine is reported as relative fluorescence units (RFU). iv) Free carbonyl groups were measured utilizing aliquots of $100 \mu \mathrm{l}$ of plasma and $1 \mathrm{ml}$ of $10 \mathrm{mmol} / \mathrm{l}$ 2,4-diphenylhydrazine (DNPH) [20]. The absorbance was measured at $370 \mathrm{~nm}$ to detect the formation of dinitrophenylhydrazones. The molar extinction coefficient for DPNH $(E=22,000 / \mathrm{M} / \mathrm{cm})$ was utilized to calculate the carbonyl concentration. v) Total protein was measured as a reference parameter by the Lowry method [21].

\section{Determination of Oxidation and Structural Changes of Insulin}

Recombinant human insulin (Lily Laboratories Mexico City, Mexico) which is also called 'native insulin' in this study was exposed to NW and 01 blood as previously described [8]. Briefly, 30 IU (1.5 mg) of native insulin was introduced into a $5-\mathrm{cm}$ portion of membrane dialysis tubing with a cutoff of 3,500 Da (Spectrum Laboratories, Inc., Rancho Dominguez, CA. USA). The dialyzing tubes were incubated at $37 \stackrel{\circ}{\circ}$ in $6 \mathrm{ml}$ of blood (from NW or 01) for $3 \mathrm{~h}$. After incubation, the bags containing insulin were washed with distilled water. $5 \mathrm{IU}(250 \mu \mathrm{g})$ of insulin were used to determine the levels of formazan and carbonyls; these determinations were performed with the same procedures indicated above. Blood effects from NW and 01 on insulin structure were analyzed by nondenaturing polyacrylamide gels. After insulin incubation in blood from obese patients, $5 \mu \mathrm{l}(90 \mu \mathrm{g})$ of insulin was diluted with an equal volume of $2 \times$ sample buffer (50 mmol/l TrisHCl, pH 6.8, $20 \%$ glycerol and $0.04 \%$ bromophenol blue) before loading onto 15\% nondenaturing polyacrylamide gels. Coomassie blue staining of polyacrylamide gels was performed to assess any changes in the electrophoretic pattern.

\section{Statistical Analysis}

Mean \pm SD values were calculated for all variables. Intragroup comparison was performed with t-parade. The intergroup comparison was performed with t-student tests. A probability value \pm 0.05 was considered statistically significant.

\section{Results}

\section{Subjects}

3201 patients and 16 NW subjects participated in this study. The characteristics of these subjects are included in table 1 .

\section{Oxidative Stress Biomarkers in Plasma}

Oxidative stress status of the study groups was evaluated by determining the values of several biomarkers of oxidative stress in plasma. Table 2 shows the values of oxidative stress biomarkers detected in plasma of the groups in study. The data obtained indicated the presence of higher levels of oxidation biomarkers in 01 patients. The lipid damage in the 01 group was higher than in NW group $(6.5 \pm 1.8$ and $4.8 \pm 2.6 \mu \mathrm{mol} / \mathrm{l}$, respectively, $\mathrm{p}<$ 0.0001); in addition, biomarkers related to protein damage (carbonyl group and dityrosine) were also higher in the 01 than in the NW group (table 2). These results showed the presence of oxidative stress in the plasma of 01 patients.

\section{Insulin Oxidation by Blood from 01 Patients}

The determination of the oxidation biomarkers in the insulin showed that the carbonyl group content was higher after incubation in blood from 01 subjects $(3.4 \pm 0.3 \mathrm{nmol}$ osazone / mg protein) than in blood from NW subjects (1.6 \pm 0.3 osazone / mg protein) (fig. $1 \mathrm{~A} ; \mathrm{p}<$ $0.001)$. A similar behavior was observed with formazan, showing higher values after incubation with blood from 01 subjects ( $82.9 \pm 6.2 \mathrm{nmol}$ formazan / mg protein) than with that from NW subjects (65.5 $\pm 4.9 \mathrm{nmol}$ formazan / mg protein) (fig. $1 \mathrm{~A} ; \mathrm{p}<0.001)$. These results suggest that blood from 01 subjects, unlike that from NW subjects, had the capacity to modify insulin. Because the system involved incubation of insulin in blood, there is the possibility that the iron liberated from hemoglobin through hemolysis could exert an 
Table 2. Plasmatic concentration of biomarkers in the groups of study ${ }^{\mathrm{a}}$

\begin{tabular}{lll}
\hline Biomarker & $\begin{array}{l}\text { Normal weight } \\
(\mathrm{N}=16)\end{array}$ & $\begin{array}{l}\text { Obese 1 } \\
(\mathrm{N}=32)\end{array}$ \\
\hline TBARS, $\mu \mathrm{mol} / \mathrm{l}$ & $4.82 \pm 2.60$ & $6.50 \pm 1.80 *$ \\
Carbonyl, nmol osazone / mg protein & $0.71 \pm 0.10$ & $1.40 \pm 0.30 *$ \\
DT, URF / mg protein & $94.18 \pm 9.90$ & $148.50 \pm 3.10^{*}$ \\
\hline
\end{tabular}

aData are expressed as means $\pm \mathrm{SD}$, analyzed by $t$ student.

$* \mathrm{p}<0.0001$.

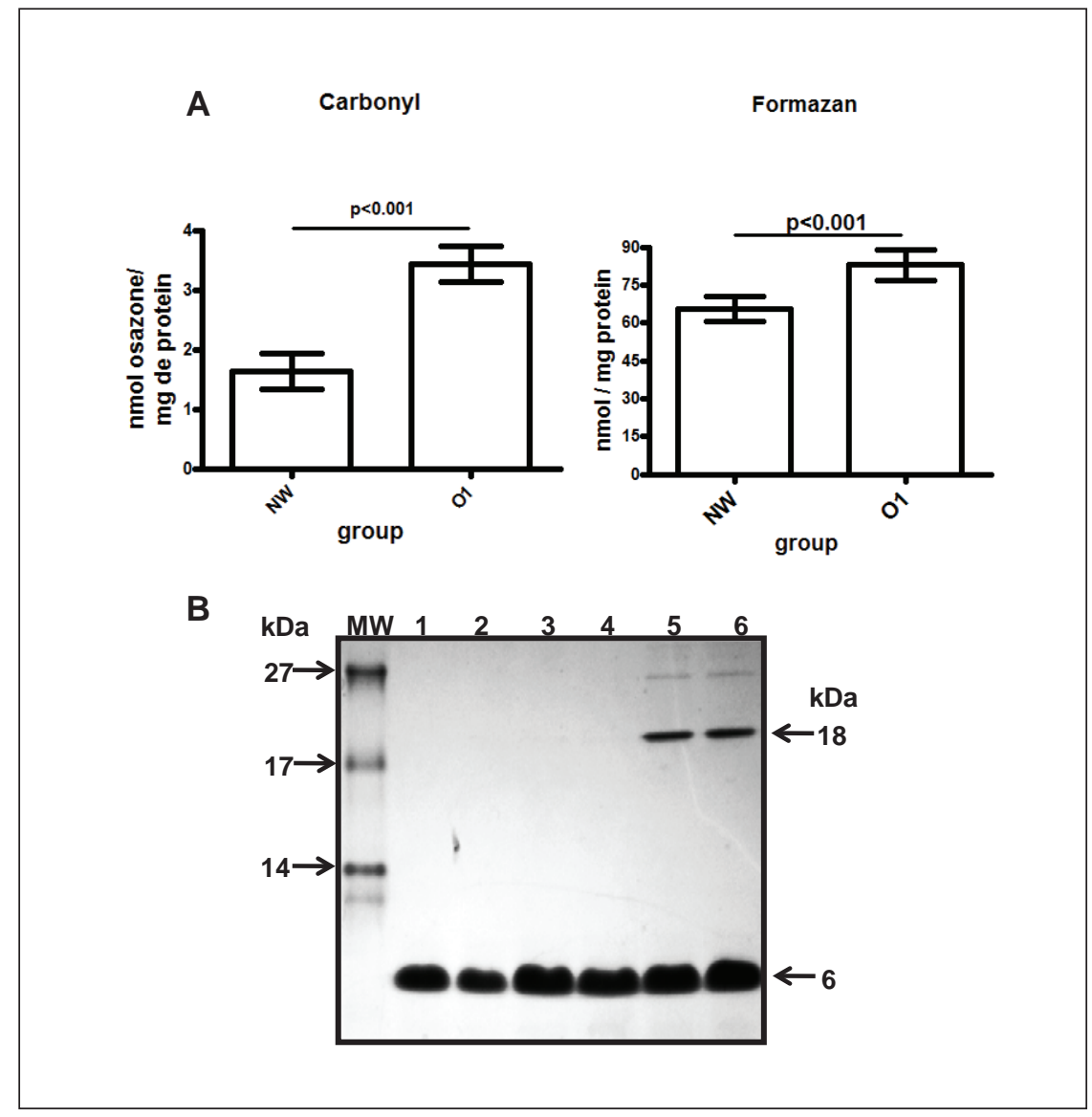

Fig. 1. Chemical and structural changes of insulin after incubation with blood from obese patients. A Higher values of carbonyl groups and formazan were generated in the insulin molecule incubated with blood from 01 subjects. Data are expressed as means \pm SD and analyzed by t students $\left({ }^{*} p<0.001\right)$. B Coomassie blue-stained nondenaturing polyacrylamide (15\%) gel of insulins incubated in blood. Lane 1 native insulin, lane 2 insulin incubated in water, lanes 3 and 4 insulin incubated in blood from NW, lane 5 and 6 insulin incubated in blood from 01 subjects. The arrow indicates an insulin polymer with an apparent molecular mass of $18 \mathrm{kDa}$. Notice that this band is only present in insulin incubated in blood from 01 patients. Molecular weight (MW) and molecular masses of the markers (kDa) are given on the left side of panel. 
Table 3. Anthropometric parameters

\begin{tabular}{|c|c|c|c|c|}
\hline \multirow[t]{2}{*}{ Anthropometric parameters } & \multicolumn{2}{|l|}{$\mathrm{HD}(\mathrm{N}=16)$} & \multicolumn{2}{|c|}{$\operatorname{HDMAE}(\mathrm{N}=16)$} \\
\hline & 0 days & 90 days & 0 days & 90 days \\
\hline Weight, kg & $87.44 \pm 16.30$ & $80.83 \pm 12.36^{*}$ & $80.46 \pm 8.55$ & $77.41 \pm 8.69^{*}$ \\
\hline BMI, kg/m² & $33.58 \pm 4.51$ & $31.25 \pm 3.95^{*}$ & $32.67 \pm 2.83$ & $31.43 \pm 3.0^{*}$ \\
\hline Body fat, $\%$ & $40.82 \pm 4.98$ & $37.70 \pm 5.62 *$ & $40.73 \pm 4.23$ & $39.21 \pm 4.18^{*}$ \\
\hline Waist circumference, $\mathrm{cm}$ & $100.72 \pm 11.33$ & $92.86 \pm 9.40^{*}$ & $96.33 \pm 6.44$ & $90.23 \pm 6.76^{*}$ \\
\hline Hip circumference, $\mathrm{cm}$ & $113.40 \pm 9.90$ & $107.86 \pm 8.58^{*}$ & $114.55 \pm 8.30$ & $108.26 \pm 7.99 *$ \\
\hline Waist-to-hip ratio & $0.88 \pm 0.07$ & $0.85 \pm 0.06^{*}$ & $0.84 \pm 0.06$ & $0.80 \pm 0.08^{*}$ \\
\hline
\end{tabular}

Data are expressed as mean SD, analyzed by group with $t$ parade ${ }^{*} \mathrm{p}<0.01$.

oxidative effect on insulin. However, we excluded this possibility by verifying the absence of hemolysis in our samples. To this end, we quantified the levels of free iron in plasma before and after the incubation period; no differences were detected when intergroup comparisons were performed (data not shown).

Because the data regarding oxidative markers in insulin suggested that there might be structural changes in the hormone after its incubation with 01 blood, we analyzed whether these chemical modifications could be observed as changes in the electrophoretic pattern of the hormone. After insulin incubation with blood from 01 subjects, $90 \mu \mathrm{g}$ of the hormone was loaded onto $15 \%$ nondenaturing polyacrylamide gels and separated by electrophoresis. Coomassie blue staining of the polyacrylamide gel was performed to assess any changes in the electrophoretic pattern that might indicate molecular damage to insulin. Fig. 1B illustrates a representative polyacrylamide gel showing the electrophoretic pattern obtained: lane 1 shows native insulin, lane 2 shows insulin incubated in water, lanes 3 and 4 show insulin incubated in blood from NW subjects, and lanes 5 and 6 show insulin incubated in blood from 01 subjects. A band of approximately $6 \mathrm{kDa}$ was present in all samples; this is consistent with the reported molecular mass of approximately $6 \mathrm{kDa}$ for insulin. Importantly, insulin samples incubated in blood from 01 patients showed a band with a molecular mass of $18 \mathrm{kDa}$ (fig. 1B, lanes 5 and 6), demonstrating the presence of structural changes in the hormone.

\section{Effects of HD and Exercise}

The effects of HD and HDMAE on obese patients were analyzed. Table 3 shows anthropometric parameters before and after the treatments; importantly, all parameters significantly decreased after the treatments $(\mathrm{p}<0.01)$. However, when oxidative stress biomarkers in plasma were analyzed, we observed that the subjects in HD treatment showed a decrease in TBARS values $(3.42 \pm 0.5 \mu \mathrm{mol} / \mathrm{l})$. The values of this marker decreased to values lower than that in NW subjects ( $4.82 \pm 0.6 \mu \mathrm{mol} / \mathrm{l})$ (table 4$)$. A similar effect of this biomarker was observed in the HDMAE group. These results suggest that the changes observed were generated by HD treatment and that the exercise did not have any additional effect. When dityrosine values were analyzed, the data showed a decrease in the HD group; however, the values did not reach those of NW subjects (table 4). In fact, an increase in this biomarker was observed in 01 patients after HDMAE treatment (table 4). Interestingly, carbonyl values were modified by both treatments, reaching values similar to those detected in NW subjects (table 4). 
Table 4. Values detected in plasma of MDA, dityrosines and carbonyl groups after HD and HDMAE treatments $^{\mathrm{a}}$

\begin{tabular}{|c|c|c|c|c|c|}
\hline \multirow[t]{2}{*}{ Biomarker } & \multirow[t]{2}{*}{$\begin{array}{l}\text { NW } \\
(N=16)\end{array}$} & \multicolumn{2}{|l|}{$\begin{array}{l}\text { HD } \\
(\mathrm{N}=16)\end{array}$} & \multicolumn{2}{|l|}{$\begin{array}{l}\text { HDMAE } \\
(\mathrm{N}=16)\end{array}$} \\
\hline & & 0 days & 90 days & 0 days & 90 days \\
\hline TBARS, $\mu \mathrm{mol} / \mathrm{l}$ & $4.82 \pm 0.60$ & $6.50 \pm 0.90$ & $3.42 \pm 0.50^{*}$ & $6.50 \pm 0.50$ & $3.48 \pm 0.70^{*}$ \\
\hline DT, URF / mg protein & $94.18 \pm 3.10$ & $133.50 \pm 13.80$ & $110.70 \pm 5.10^{*}$ & $132.70 \pm 5.90$ & $151.90 \pm 19.58$ \\
\hline Carbonyl, nmol osazone / mg protein & $0.71 \pm 0.10$ & $1.68 \pm 0.20$ & $0.76 \pm 0.03^{*}$ & $2.47 \pm 0.40$ & $0.68 \pm 0.06^{*}$ \\
\hline
\end{tabular}

aData are expressed as means \pm SD analyzed by t student for group. 0 vs. 90 days.

$* \mathrm{p}<0.01$

\section{Insulin Oxidation after Treatments}

Because oxidative stress biomarkers decreased in the blood of obese patients after the treatments, we evaluated whether these changes could be related to a decrease in the molecular damage detected in insulin (fig. 1). Recombinant human insulin was incubated in the blood from 01 patients obtained after the treatments, and the biomarkers of oxidation in the hormone were analyzed. Fig. 2A shows the values of carbonyl and formazan products detected in insulin. The generation of carbonyl groups by blood from 01 patients decreased by $46 \%$ after HD treatment (before $3.5 \pm 0.23$, after $1.88 \pm 0.37 \mathrm{nmol}$ osazone / $\mathrm{mg}$ protein). Interestingly, a greater effect was observed in subjects treated with HDMAE (59\%) (before $3.38 \pm 0.72$, after $1.43 \pm 0.38 \mathrm{nmol}$ osazone / mg protein). However, the decreased generation of formazan products was only statistically significant with blood from 01 subjects treated with HDMAE (before $75.4 \pm 6.1$, after $54 \pm 3.1 \mathrm{nmol}$ formazan / mg protein) (fig. 2A). These data suggest that both treatments decreased the capacity of blood to induce molecular damage. Because the incubation of recombinant human insulin in blood from 01 subjects induced the formation of a polymer of insulin (fig. 1B, lanes 5 and 6), we investigated whether HD or HDMAE treatments could prevent these effects. Recombinant human insulin was incubated in blood from 01 subjects obtained after treatment, and the electrophoretic pattern of the hormone was analyzed by electrophoresis. Fig. 2B illustrates a representative polyacrylamide gel showing the electrophoretic pattern obtained: lane 1 shows insulin incubated in blood from an 01 subject before treatment, and lane 2 shows insulin incubated in blood from an 01 subject after treatments. A band of approximately $6 \mathrm{kDa}$ was present in all samples (insulin); however, the band of the polymer of insulin $(18 \mathrm{kDa})$ which was generated by blood samples from 01 subjects before treatment (fig. 2B, lane 1), decreased or, in some cases, even vanished after incubation with blood from 01 subjects after treatment (fig. $2 \mathrm{~B}$, lane 2). These results suggest that the decrease in the biomarker values of oxidative stress in plasma is associated with a lower capacity of plasma to generate molecular damage.

\section{Discussion}

Although much research has been conducted to investigate the relationship between obesity and oxidative stress, most of the current obesity studies have not been aimed to prevent systemic oxidative stress in obese patients. In the present study, our data demon- 


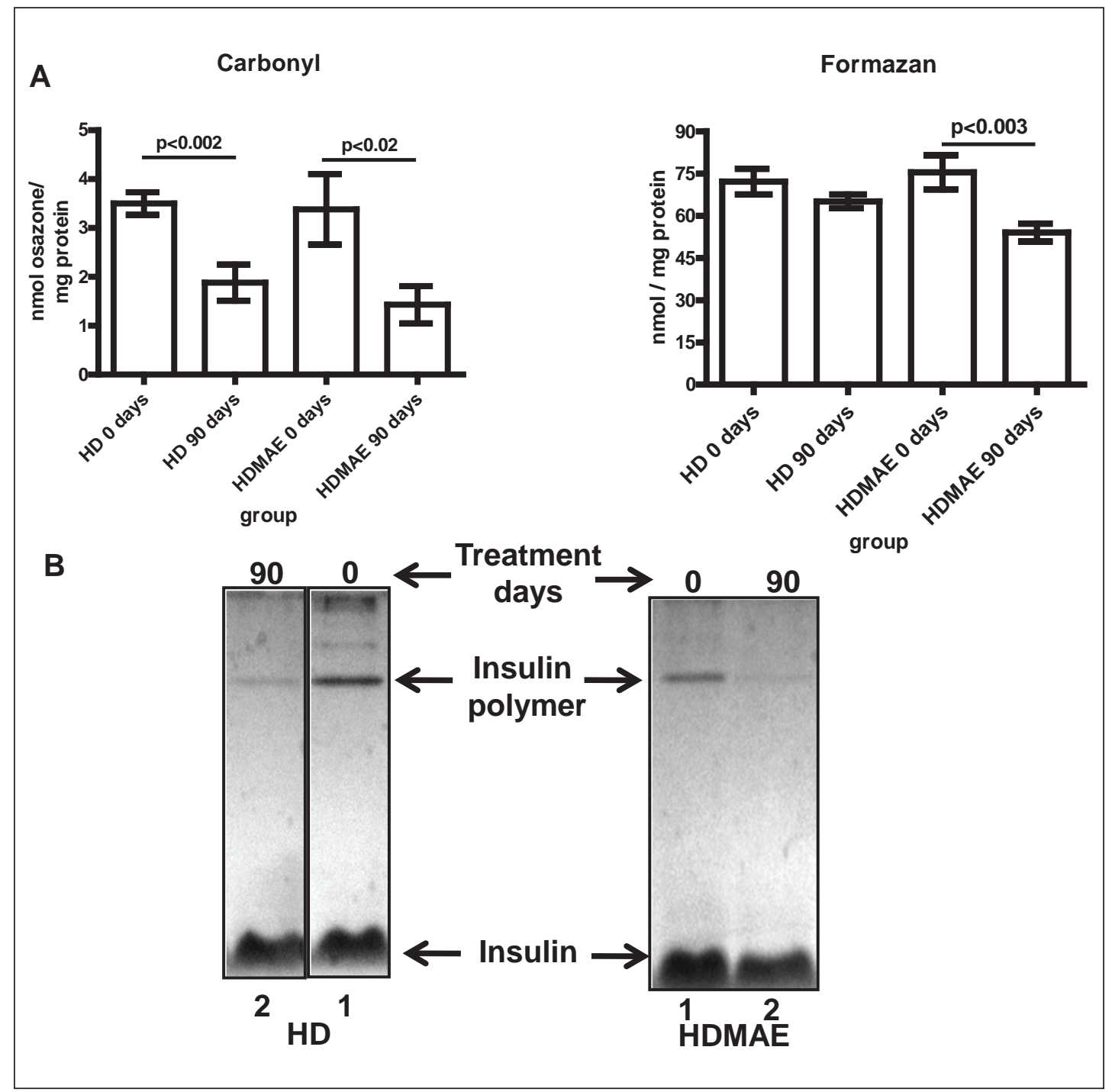

Fig. 2. Insulin modifications after incubation in blood from obese subjects with HD and HDMAE treatments. A Lower values of carbonyl groups and formazan products were generated by blood from obese patients after HD and HDMAE treatments (90 days). Data are expressed as means \pm SD and analyzed by t parade ( $\left.{ }^{*} \mathrm{p}<0.003\right)$. B Coomassie blue-stained nondenaturing polyacrylamide (15\%) gel of insulins incubated in blood from an obese subject. Lanes 1, insulin incubated in blood from 01 patients. The arrow indicates the insulin polymer (18 kDa). Lanes 2, insulin incubated in blood from an 01 patient after HD and HDMAE treatments. Notice that the insulin polymer was decreased in both bloods; however, insulin polymer generation was lower in blood from 01 patients treated with HDMAE.

strate that HD treatment (with 20\% caloric restriction) helped obese patients to decrease anthropometric parameter values and weight. Interestingly, the effects generated by HD treatment were accompanied by a decrease in oxidative stress biomarkers in plasma, an observation that supports earlier results showing an effect of diet and macronutrient intake on oxidative stress and inflammation [10].

This observation has important implications, because lower oxidative damage to proteins such as LDL-C and insulin or the prevention of pathologic processes in which oxidative stress plays an important role (atherosclerosis) should be considered in managing 
obesity. It is important to mention that HD treatmentgenerated important beneficial changes in obese patients. However, the inclusion of exercise of moderate intensity in the treatment induced an adaptation in the antioxidant capacity and in consequence a greater resistance to oxidative damage $[22,23]$. In this context, the data showed that the weight loss induced by HD treatment had a significant effect on TBARS, which is one of the most frequently used indicators of lipid peroxidation [24]. This result is in agreement with the finding of Crujeiras et al. [25], who observed a marked decrease in malondialdehyde with HD in obese patients. Because high levels of lipid peroxidation has been associated with a greater risk for developing heart diseases [26,27], the reduction of TBARS levels in obese patients by HD treatment would also be a significant advantage in the management of obesity.

Thus, in this study we provide evidence that HD treatment generates significant beneficial effects in obese patients with respect to loss of body weight and anthropometric parameters. When combining HD treatment with regular moderate aerobic exercise (HDMAE), an additional benefit with respect to oxidative stress resistance could be achieved, resulting in a reduction of the blood's ,capacity to induce a molecular damage, which is in accordance with earlier reports that indicate that aerobic exercise of moderate intensity generates an increasing resistance to oxidative stress $[28,29]$. Thus, HDMAE treatment (even after a short time period of 3 months) could generate a better level of health in obese patients than HD alone. The weight loss observed with HDMAE treatment was accompanied by a fat mass loss and a decrease in oxidative stress biomarkers, which is associated with the lower capacity of the blood of these patients to induce molecular damage. These findings are in line with those showing that excess fat is involved in the generation of oxidative stress [30]. Even if it has been suggested that physical exercise rather than an energy-restricted diet could be recommended as an essential method for body weight reduction [31,32], in this work we showed that the protective benefit generated by HD treatment could be reinforced by regular moderate aerobic exercise. This benefit could to be related to an induction of antioxidant enzymes. Although these enzymes were not measured, elevation of enzyme activity might have occurred as has been reported by de Lemos et al. [33] and Radák et al. [23]. This clearly shows that physical activity has benefits for obese patients. On the other hand, there is some evidence that intensive workout resulting in oxidative stress leads to skeletal muscle injury caused by the generation of reactive oxygen species $[34,35]$. Therefore, estimating the risk of oxidative stress induced by exercise seems to be important for planning the intensity of physical activity in obese patients. We therefore propose to check the oxidative stress resistance after a first 3-month cycle of HDMAE prior to an enhancement in the intensity of exercise. As shown in this study, such a short cycle of HDMAE results in an increase of the serum antioxidant capacity, allowing a faster adaptation of obese patients to intensive exercise-induced oxidative stress by attenuating the degree of change and by reducing the frequency of adverse effects during the treatment. Moreover, in individuals who are particularly susceptible to exerciseinduced oxidative stress or in whom intensive exercise is not advisable because of a low efficiency of their cardiovascular system and a high incidence of hypertension, this treatment could be an alternative approach.

\section{Disclosure Statement}

The authors declared no conflicts of interest. 


\section{References}

1 McGill HC Jr, C McMahan A, Herderick EE, Zieske AW, Malcom GT, Tracy RE, Strong JP: Obesity accelerates the progression of coronary atherosclerosis in young men. Circulation 2002;105:2696-2698.

- 2 Reaven GM: All obese individuals are not created equal: insulin resistance is the major determinant of cardiovascular disease in overweight/obese individuals. Diab Vasc Dis Res 2005;2:105-112.

- 3 Tilg H, Moschen AR: Inflammatory mechanisms in the regulation of insulin resistance. Mol Med 2008;14: 222-231.

- 4 Ghanim H, Aljada A, Daoud N, Deopurkar R, Chaudhuri A, Dandona P: Role of inflammatory mediators in the suppression of insulin receptor phosphorylation in circulating mononuclear cells of obese subjects. Diabetologia 2007;50:278-285.

5 Furukawa S, Fujita T, Shimabukuro M, Iwaki M, Yamada Y, Nakajima Y, Nakayama O, Makishima M, Matsuda M, Shimomura I: Increased oxidative stress in obesity and its impact on metabolic syndrome. J Clin Invest 2004;114:1752-1761.

6 Garcia-Bailo B, El-Sohemy A, Haddad PS, Arora P, Benzaied F, Karmali M, Badawi A: Vitamins D, C, and E in the prevention of type 2 diabetes mellitus: modulation of inflammation and oxidative stress. Biologics 2011;5:7-19.

- 7 Ernst MC, Sinal CJ: Chemerin: at the crossroads of inflammation and obesity. Trends Endocrinol Metab 2010;21:660-667.

- 8 Montes-Cortes DH, Hicks JJ, Ceballos-Reyes GM, Garcia-Sanchez JR, Medina-Navarro R, Olivares-Corichi IM: Chemical and functional changes of human insulin by in vitro incubation with blood from diabetic patients in oxidative stress. Metabolism Clinical and Experimental 2010;59:935-942.

- 9 Sigal RJ, Kenny GP, Wasserman DH, Castaneda-Sceppa C, White RD: Physical activity/exercise and type 2 diabetes: a consensus statement from the American Diabetes Association. Diabetes Care 2006;29:14331438.

10 Dandona P, Ghanim H, Chaudhuri A, Dhindsa S, Kim SS: Macronutrient intake induces oxidative and inflammatory stress: potential relevance to atherosclerosis and insulin resistance. Exp Mol Med 2010;30,42: 245-53.

11 Lwow F, Dunajska K, Milewicz A, Jedrzejuk D, Kik K, Szmigiero L: Effect of moderate-intensity exercise on oxidative stress indices in metabolically healthy obese and metabolically unhealthy obese phenotypes in postmenopausal women: a pilot study. Menopause 2011;18:646-653.

12 Teixeira-Lemos E, Nunes S, Teixeira F, Reis F: Regular physical exercise training assists in preventing type 2 diabetes development: focus on its antioxidant and anti-inflammatory properties. Cardiovasc Diabetol 2011;10:12.

13 Vincent KR, Vincent HK, Braith RW, Lennon SL, Lowenthal DT: Resistance exercise training attenuates exerciseinduced lipid peroxidation in the elderly. Eur J Appl Physiol 2002;87:416-423.

$\checkmark 14$ Kelley GA, Kelley KS, Tran ZV. Aerobic exercise and lipids and lipoproteins in women: a meta-analysis of randomized controlled. trials. J Womens Health (Larchmt) 2004;13:1148-1164.

15 Vincent KR, Vincent HK, Braith RW, Bhatnagar V, Lowenthal DT. Strength training and hemodynamic responses to exercise. Am J Geriatr Cardiol 2003;12:97-106.

-16 Castaneda C, Layne JE, Munoz-Orians L, Gordon PL, Walsmith J, Foldvari M, Roubenoff R, Tucker KL, Nelson ME: A randomized controlled trial of resistance exercise training to improve glycemic control in older adults with type 2 diabetes. Diabetes Care 2002;25:2335-2341.

$\checkmark 17$ Yagi K: Sample procedure for specific assay of lipid hydroperoxides in serum or plasma. Methods Mol Biol 1998;108:107-110.

18 Gieseg SP, Simpson JA, Charlton TS, Duncan MW, Dean RT: Protein-bound 3,4 dihydroxyphenylalanine is a major reductant formed during hydroxyl radical damage to proteins. Biochemistry 1993;32:4780-4786.

19 Lehrer SS, Pasman GD: Ultraviolet irradiation effects in poly-L-tyrosine and Model Compounds. Identification of Bityrosine as a Photoproduct. Biochemistry 1967;6(3):757-767,

-20 Reznick AZ, Packer L: Oxidative damage to proteins: spectrophotometric method for carbonyl assay. Methods Enzymol 1994;233:357-363.

21 Lowry OH, Rosebrough NJ, Farr AL, Randall RJ: Protein measurement with the Folin phenol reagent. J Biol Chem 1951;193:265-275.

-22 Falone S, Mirabilio A, Pennelli A, Cacchio M, Di Baldassarre A, Gallina S, Passerini A, Amicarelli F: Differential impact of acute bout of exercise on redox- and oxidative damage-related profiles between untrained subjects and amateur runners. Physiol Res. 2010;59:953-961.

23 Radák Z, Chung HY, Goto S: Systemic adaptation to oxidative challenge induced by regular exercise. Free Radic Biol Med. 2008;44:153-159.

-24 Nielsen F., Mikkelsen B. B., Andersen HR \& Grandjean. P: Plasma Malondialdehyde as biomarker for oxidative stress: reference interval and effects of life style factor. Clin Chem 1997;43:1209-1214.

25 Crujeiras AB, Parra D, Abete I, Martínez JA: A hy pocaloric diet enriched in legumes specifically mitigates lipid peroxidation in obese subjects. Free Radic Res 2007;41:498-506. 
-26 Negre-Salvayre A, Auge N, Ayala V, Basaga H, Boada J, Brenke R, Chapple S, Cohen G, Feher J, Grune T, Lengyel G, Mann GE, Pamplona R, Poli G, Portero-Otin M, Riahi Y, Salvayre R, Sasson S, Serrano J, Shamni O, Siems W, Siow RC, Wiswedel I, Zarkovic K, Zarkovic N: Pathological aspects of lipid peroxidation. Free Radic Res 2010;44:1125-1171.

27 Fraley AE, Tsimikas S: Clinical applications of circulating oxidized low-density lipoprotein biomarkers in cardiovascular disease. Curr Opin Lipidol 2006;17:502-509.

28 Cooper CE, Vollaard NB, Choueiri T, Wilson MT: Exercise, free radicals and oxidative stress. Biochem Soc Trans 2002;30:280-285.

$\checkmark 29$ Lwow F, Dunajska K, Milewicz A, Jedrzejuk D, Kik K, Szmigiero L: Effect of moderate-intensity exercise on oxidative stress indices in metabolically healthy obese and metabolically unhealthy obese phenotypes in postmenopausal women: a pilot study. Menopause 2011;18:646-653.

30 Furukawa S, Fujita T, Shimabukuro M, Iwaki M, Yamada Y, Nakajima Y, Nakayama O, Makishima M, Matsuda M, Shimomura I: Increased oxidative stress in obesity and its impact on metabolic syndrome. J Clin Invest 2004;114:1752-1761.

-31 Wildman RP: Healthy obesity. Curr Opin Clin Nutr Metab Care 2009;12:438-443.

-32 Perseghin G: Is a nutritional therapeutic approach unsuitable for metabolically healthy but obese women? Diabetologia 2008;51:1567-1569.

33 de Lemos ET, Reis F, Baptista S, Garrido AP, Pinto R, Sepodes B, Vala H, Rocha-Pereira P, Silva AS, Teixeira F: Efeitos do exercício físico aeróbio no perfil metabólico e oxidativo de ratos diabéticos tipo 2. Bull SPHM 2007,22:16-28.

34 Alessio HM. Oxidative stress and muscle size, type and action; in Alessio HM, Hager man AE (eds): Oxidative Stress, Exercise and Aging. London, Imperial College Press, 2006, pp 25-57.

-35 Powers SK, Malcom JJ: Exercise-induced oxidative stress: cellular mechanisms and impact on muscle force production. Physiol Rev 2008;88:1243-1276. 